http://dx.doi.org/10.12795/PH.1989.v04.i02.22

\title{
CONSTRUCCIÓN Y MECÁNICA DEL CUERPO LIBERTINO EN SADE. EXPERIENCIA DEL DESEO.
}

M. Concepción Pérez y Pérez

La amplitud del alcance subversivo de la figura de Sade no puede ser medida si no se sitúa al autor dentro del contexto ideológico-filosófico adecuado. Como la crítica sadiana ha puesto de manifiesto, la voz de Sade, que grita desde la oscuridad de su eterna prisión en los últimos decenios del XVIII, llevará hasta su propio límite los planteamientos materialistas de la filosofía de la época, desmontando sus estrategias, al tiempo que se realiza un proceso radical de demolición de todo el edificio sobre el que asienta sus bases y se arraiga la conciencia del statu quo. Tanto ésta, basada, en el plano religioso, en la trascendencia, que intenta explicar las dimensiones inexplicables del ser humano, como la conciencia materialista, que niega la dimensión trascendente para asumir la explicación total del hombre desde la inmanencia, pretenden instaurar un orden que integre el Yo en el Cosmos y en la Historia, que regule y articule en una relación armónica el complejo generado a partir de la dialéctica entre individuo y sociedad.

Ahora bien, es precisamente contra este orden contra el que se eleva la voz de Sade. La era de la energía, en la que se sitúa la producción del autor, abriendo una nueva crisis en la conciencia colectiva, ve tambalearse la imagen reconstruida del universo a lo largo del siglo. El universo, en perpetuo devenir, es un complejo de fuerzas y tensiones en continua mutación ${ }^{1}$.

1 Cf. Michel Delon, L'idée d'énergie au tournant des Lumières (1770-1820), París, P.U.F., 1988. La obra de Sade no puede ser comprendida sin tener en cuenta la presencia de la energía, pues es un principio activo a través del cual se ensueña la realidad, se genera el metadiscurso y se construye el universo de ficción, siendo el principio que confiere coherente a todos los niveles del texto. Es lo que hemos intentado poner de manifiesto en un artículo «La energía, principio vertebrador en la estructura narrativa y simbólica del texto sadiano», aparecido en el no 2 de la revista Discurso, de la Asociación Andaluza de Semiótica. 
La idea de orden - los críticos de Sade no se cansan de observarlo, y es el primer elemento que salta a la vista ante el lector- es esencial en el universo sadiano. Pero se trata de un orden subvertido, reconstruido a partir de un proceso complejo generado por la infraestructura psicosensorial del yo, de un orden oximorónico que integra la estructura misma del desorden, reproduciendo el equilibrio cósmico. El «sadismo» no es otra cosa que la traducción en energía humana, y a través de la radicalización del deseo en la ensoñación de la escritura, de las grandes fuerzas cósmicas.

Ello cristaliza en una concepción del Yo como absoluto, pues la única realidad cierta es aquélla que es percibida a través de los sentidos, y el ámbito de la sensación es radicalmente intransitivo. Por otra parte, la proyección de la sensibilidad individual sobre los demás conduce, en el discurso sadiano, a la dispersión de la energía, y, por tanto, a su desactivación. La sensibilidad debe estar concentrada sobre el Yo, con el fin de provocar la expansión de la sensación, lo que lleva a la negación de las grandes virtudes sociales comúnmente admitidas en aras de la solidaridad universal, así como del sentimiento - amistad y amor- como dos núcleos básicos de error conducentes a la alienación del yo auténtico, Yo absoluto.

El amor se revela como piedra de toque vital en la aspiración del siglo a la felicidad, siendo llevado hasta la apoteosis. Existe, junto a una vertiente crítica de carácter realista, toda una gran corriente idealista, cuya fuerza aumenta a medida que el siglo avanza, construyendo una mitología del amor, basada en la Naturaleza y la virtud, que hace de aquél un absoluto: quintaesencia de la Naturaleza, el amor redime al hombre, instaurándose él mismo en virtud que impone su propia moral. Hacia finales de siglo, el proceso de idealización deriva hacia la mística ${ }^{2}$.

Sade reacciona contra este idealismo progresivo, insertándose, de manera radical, en la corriente crítica realista. Pero si bien ésta se resuelve en cinismo, y en una concepción, de hecho, práctica, del amor, en Sade la desarticulación analítica desemboca en destrucción y negación, tanto más violenta cuanto más se intensifica el proceso mitificador.

Con ello se pretende desenmascarar la auténtica realidad que subyace bajo el pretendido amor, pues ésta no es otra que el deseo sexual, camuflado por la estrategia de la retórica.

Pero si el deseo constituye su base real, y dicha base, por su sola esencia, es momentánea, los efectos son, sin embargo, perdurables, siendo en esta perdurabilidad, que transforma el deseo en sentimiento, en estado del alma, donde radica para Sade la peligrosidad y nocividad del amor, al generar una relación de subordinación en cuya dialéctica el Yo como esencia queda diluido. Si para la conciencia general el gran riesgo del amor-pasión consiste en la alienación del individuo, mientras que el amor-sentimiento constituye un lugar seguro, para Sade, por el contrario el sentimiento aparece como el lugar donde el Yo es absorbi-

2 Cf. Robert Mauzi, L'idée sur le bonheur dans la littérature et la pensée française au XVIIIE siècle, París, Armand Colin, 1969. 
do en su propia alienación, generado como resultante una situación de dependencia existencial, una pérdida de dominio sobre la propia conciencia. Para él, como para Buffon, el componente físico es el único válido.

Frente a la dialéctica transitiva del amor, la dialéctica intransitiva del sexo sadiano invierte la relación de subordinación, de tal manera que es el otro el que es asimilado, cubriendo una función instrumental como objeto destinado al consumo del Yo, traducido en «jouissance», cuya realidad es estrictamente incomunicable, imposible de compartir. Emanación absoluta del Yo, su búsqueda y apropiación será, por tanto, siempre individual.

La hiperactividad de la sensación marca el objetivo y la dinámica de la praxis existencial del hombre, el cual debe multiplicar la intensidad de la realidad sensorial, esto es, imprimirle un movimiento expansivo. Para ello, debe cambiar continuamente de objeto de placer, sin encadenarse jamás a un objeto único, en una teoría contra-rousseauniana del amor: si para aquél éste se dispersa de un amor indiferenciado sin pasión, para Sade los términos son invertidos, y la dirección de la tendencia se sitúa hacia una pasión indiferenciada sin amor.

En este siglo de la sociabilidad, en el que no se concibe el hombre solo, en el que el otro es otro yo, semejante a mi mismo, cuya presencia desvela mi propia identidad, el prójimo es para Sade, y paradójicamente, el ser más lejano, el perfecto extranjero. Alejándose de los filósofos materialistas en los que. se inspira, y llevando sus planteamientos hasta el límite, la esencia humana natural se sitúa en la intransitividad radical. Si para algunos espíritus de la época, como para Diderot, el orden de interconexión del universo social responde, en definitiva, al orden del universo cósmico, para el filósofo libertino el universo humano no es multinuclear, sino monocéntrico, regido, a partir de la idea de Naturaleza como base conceptual, por la ley primaria de egoísmo, sentimiento éste que la conciencia general del siglo desestima, por considerarlo estéril y de carácter negativo en la búsqueda de la felicidad.

El acto sexual aparece entonces como la actividad humana por excelencia, en la que el individuo realiza el destino cósmico impuesto por la Naturaleza ${ }^{3}$. Concentración suprema de energía, subsume y reordena toda la energía pasional ${ }^{4}$, siendo además el acto én el que el Yo, en su voluntad de dominio, se ensueña como único (de ahí, por otra parte, que el placer no puede ser compartido, pues establecería irremediablemente un nexo de igualdad con el semejante).

Ahora bien, la potencialidad activa del sexo es nula si previamente la mente no ha sido liberada. Si la imaginación, de manera preferente en la época, se sitúa en función de la voluptuosidad del sentimiento íntimo, siendo a menudo una alternativa de evasión, la imaginación libertina, ligada esencialmente al movimien-

3 «[...] Dans tous les cas on s'en donne; on fout dans tous les cas, cher amour, parce que nous sommes nées pour foutre, que nous accomplissons les lois de la nature en foutant, et que toute loi humaine qui s'écarterait de celles de la nature ne serait faite que pour le mépris», aconseja la libertina Mme. de Saint-Ange a Eugenie, en el proceso de instrucción a que es sometido el sujeto de iniciación. (La Philosophie dans le boudoir, París, Gallimard, col. «Folio», 1976, p. 92).

4 «L'acte de la jouissance est une passion qui, j'en conviens, subordonne à elle toutes les autres, mais qui les reunit en même temps...» (Ibíd., p. 260). 
to, es un activador básico que provoca o potencia la acción, centrada ésta esencialmente en una práctica que va a concebirse en función de una erótica del Mal donde queda condensada la estructura de la transgresión. El libertinaje permite entonces una vuelta al estado puro primitivo, así como una liberación del inconsciente. El comportamiento del libertino se justifica, y justifica, en una relación recíproca, en un sistema ideológico-filosófico consistente en la recodificación racional del significante sensorial: el cuerpo como significante genera significado (este alcanzará sus últimas consecuencias, en función de una lectura simbólica, en la escena libertina, teatro puro de los cuerpos). La razón no es el agente equilibrador, sino el recodificador semántico que libera la acción. El tríptico razónsentimiento-virtud, que para la conciencia general de la época se presena como alternativa preferencial en el dilema existencial de la felicidad, queda subvertido: la razón justificada el desbordamiento de la sensación desencadenando la dinámica del vicio, la cual, como dinámica de la energía, construye la estructura semántica de la virtud auténtica en estructura libertina, recuperando así el sentido etimológico del semema (virtus, como fuerza). El complejo del Crimen (entendiendo por tal toda acción realizada en función de una transgresión voluntaria y consciente contra el statu quo)se imbrica entonces en el complejo de Eros, pues el sexo ocupa el núcleo capital del que todo deriva y en el que todo confluye, al catalizar la acción subversiva del individuo: la víctima es cuerpo del deseo al tiempo que metonimiza el statu quo, destruido y subvertido en su carne.

En la dialéctica actancial que se genera en el universo narrativo, la focalización, se centra en el enfrentamiento entre libertino y víctima. La dialectica es en todos los casos generada por el primero, como ser de la energía, materializada en un movimiento continuo, a imagen de la Naturaleza. El proceso, por tanto, es indetenible, pues el libertino necesita constantemente de un alimento que ponga en marcha la operación metabólica ${ }^{5}$.

En este proceso metabólico, rápido como toda acción en el sujeto que lo produce, el alimento se consume al mismo tiempo que se ingiere, y, como dicho consumo es necesario, y constituye al mismo tiempo su finalidad, el triunfo sobre la víctima ha de ser, por tanto, hipótesis realizable. No se trata de medir fuerzas en la lucha, sino de demostrar superioridad, razón que ya de por sí motiva la elección de la víctima por parte del libertino (de ahí que responda necesariamente a una morfología precisa).

Así pues, si bien el Yo libertino, como Yo absoluto, empieza y acaba en sí mismo, y hacia él todo queda subordinado, para su realización la presencia del otro es necesaria en función de una relación de absorción, de una aniquilación que desencadena el mecanismo de la «jouissance». El otro, materia de asimilación, es entonces objeto aprehensible, al asimilarse al propio Yo.

5 «Un caractère comme celui de Granwel n'aime pas comunément à languir; les difficultés l'irritent, mais celles qui ne peuvent se vaincre éteignent les passions dans une telle âme, au lieu de les enflammer; et comme il faut à ces sortes d'individus un aliment perpétue, l'objet changerait sans doute, si l'idée du triomphe s'anéantissait sans espoir». Miss Henriette Stralson ou les effets du désespoir, in Les Crimes de l'amour, Oeuvres Complètes du Marquis de Sade, Paris, Téte de Feuilles, 1973, vol. X, p. 137. 
Esta depredación se hace posible gracias a la acción centralizadora positiva de la energía. De tal manera que, en lo concerniente a la víctima, la aprehensión de otro no es factible, pues el movimiento en función de la alteridad, verificado siempre en acciones no energéticas, traducibles en la ética de la bondad, no va a permitir la integración del otro, sino, por el contrario, la integración, en la total alienación, del Yo en el otro, pues además, el movimiento del objeto asimilable hacia el sujeto depredador predispone al ensamblaje perfecto entre libertino y víctima. La resultante que se obtiene es la afirmación del Yo libertino, construida sobre la negación del Yo victimal. La acción de la energía genera un yo activo en el primer caso; su ausencia un yo pasivo en el segundo. El yo pasivo no puede aprehender al otro, mientras que el activo sólo puede hacerlo en función de la destrucción (ello no deja de ser materia de reflexión para una lectura profunda, pues implica, ni más ni menos, que el otro es siempre el gran desconocido. Libertino y víctima son dos perfectos extraños, dos extranjeros que no se conciben mutuamente).

El juego experimental que el libertino mantiene con la víctima (el teatro del Mal es un teatro experimental) es posible gracias a la asombrosa capacidad de elasticidad de ésta (de ahí que en su morfología uno de los rasgos en los que se fija de manera preferente el ojo libertino sea precisamente la elasticidad corporal). En la dialéctica actancial se produce un proceso de catálisis que genera, en base a un endurecimiento, una extraordinaria capacidad de resistencia en la víctima, alcanzando, como muy bien observa Lucette Finas, dimensiones hiperbólicas $^{6}$ : la debilidad definitoria se transforma en fuerza; la materia blanda es moldeable, convirtiéndose en materia dura a medida que la tensión generada en la dialéctica va transformándose en hipertensión.

De este modo, el endurecimiento victimal consiste en una energetización a partir de la acción generada por el libertino, actante de la energía, pues es él quien saca a la víctima de su inmovilismo existencial para someterla a una serie de sacudidas energéticas, obligándola, por otra parte, a colaborar de manera activa en la macrotarea erótica: Justine, al igual que todas las víctimas de las orgías libertinas, se verá obligada a participar activamente, como obrera, en el sistema de producción erótico libertino, donde no tiene cabida el elemento inútil. El proceso de experimentación sobre el cuerpo victimal que se lleva a cabo en la escena libertina, destinado en principio al manejo en función de su capacidad de resistencia y las múltiples posibilidades que plantea, se inscribe dentro del gran proceso de abstracción geométrica a partir del cual se ensueña la realidad, creándose, a través de la escritura, una realidad nueva ${ }^{7}$. Por otra parte, la agresión sobre la víctima que se lleva a cabo de manera sistemática en la Orgia libertina permite la liberación absoluta de la energía pulsional, la realización de la ensoñación de poder del Yo, el triunfo sobre las fuerzas oscuras de la existencia y la destrucción

6 Cf. Lucette Finas, «L'increvable féminin dans Faxelange ou les torts de L'ambition,, in Sade, écrire la crise (coloquio de Cerisy, 1981), Paris, Belfond, 1983.

7 Dicho proceso se observa, desde el nivel de la infraestructura psicosensorial del texto, en la ensoñación generada por el Yo de la escritura que se plasma en la disposición de los cuadros eróticos así como en la percepción de la realidad a través de la descripción y construcción del espacio. 
— simbólica- del statu quo, como sistema de represión y aberración, que pervierte la verdadera esencia natural del individuo al integrarle en la esfera de los intereses colectivos.

Todo ello cristaliza, en la ensoñación narrativa, en la construcción, sobre los distintos cuerpos que componen la escena libertina, de lo que los críticos sadianos suelen denominar «máquina erótica». La denominación es, en verdad, enteramente acertada, pues la máquina dispone un sistema de ajustes perfectos, construyéndose como una auténtica máquina de precisión, en la que merece la pena que detengamos nuestra atención.

La máquina erótica sadiana se construye a partir de la disposición grupal de los cuerpos. Este sexo, cuya intransitividad se reivindica y asume hasta sus últimas consecuencias, se construye, sin embargo, como una estructura socializada. La composición final del cuerpo, llevada a cabo a partir de un proceso selectivo de segmentación y reconstrucción, conlleva la privilegiación y utilización exclusiva de ciertas partes constitutivas y la total abolición de otras: se expulsa de la composición todo aquello que no sea sexo. El planteamiento mecanicista-materialista de la filosofía de Sade lleva a una concepción del hombre como complejo bioenergético. No es el alma, sino el «fluide électrique» que circula en las concavidades del sistema nervioso, lo que anima al ser humano, determinando la actividad, el comportamiento y el carácter del individuo. La electrización más poderosa, que sacude toda la naturaleza humana, inserta en la Naturaleza cósmica, es la sacudida sexual.

Por ello, el sexo se construye como metoninia de la totalidad del ser humano. Se le privilegia de una manera directa y excluyente, escapando a la persisividad de la estrategia metafórica, única tolerada por el statu quo ${ }^{8}$. El libertino, como encarnación - en sentido propio- de energía viva, desarrolla una actividad sexual indetenible. "Toujours en rut», el fluido espermático se exhala a través de cada uno de sus poros ${ }^{9}$. «Le foutre» es entonces metabolización de la energía cósmica en el hombre, al tiempo que fluido eléctrico que establece la conexión entre los distintos elementos dispuestos como núcleos energéticos en el microsistema del cuerpo libertino.

La composición numérica de los sujetos integrados en la maquina erótica genera distintos modos de conexión corporal, que van desde la formación simple hasta la articulación de un cuerpo complejo. El modo más simple de conexión corporal es aquel en que una única víctima se integra en la economía de un solo libertino. Se trata, desde el punto de vista de la frecuencia, del modo de conexión más raro y que, de hecho, tiende a evitarse, pues la ensoñación más rica se construye, como señalaba, sobre un cuerpo múltiple. Cuando un libertino único posee un serrallo, el cuerpo victimal será, preferentemente, plural.

La segmentabilidad del cuerpo de la víctima plantea múltiples posibilidades de conexión. Un solo cuerpo puede conectar a varios libertinos. La energía se con-

8 O, lo que es peor, subvirtiéndola a partir de su yuxtaposición con el código referencial directo.

9 «Sylvestre furieux... Sylvestre qui bandait comme un âne et dont le foutre s'exhalait par tous les pores». La Nouvelle Justine, O. C., vol. VII, p. 80. 
centra entonces sobre una sola víctima, saturando el cuerpo. El mejor ejemplo de saturación de este tipo lo encontramos en la escena de recepción de Justine a la abadía benedictina de Sainte-Marie-des-bois en la tercera versión del texto, donde, tras el reparto del cuerpo entre los distintos agentes, la máquina se construye sobre Justine.

La formación de este cuerpo complejo y múltiple es, por otra parte, hacia donde se encamina toda la dinámica energética desarrollada en los ataques individuales a lo largo de la citada escena. A la concentración de los seis cuerpos sobre la víctima hay que añadir el refuerzo proporcionado por los microsistemas corporales construidos alrededor de cada libertino: la energía proporcionada se concentra sobre cada agresor, multiplicándose, para hacerlo a su vez sobre la víctima, multiplicándose entonces por seis.

Esta prodigiosa concentración de energía es la razón preferente de la necesidad de un macrocuerpo plural: la concentración energética, como la solar, destruye el objeto sobre el que se fija, como explica el libertino Noirceuil, auténtico sol negro, ante Juliette ${ }^{10}$.

La destrucción está reservada a la víctima (en el pasaje al que aludimos el ofrecimiento de Juliette es rechazado por el libertino con el fin de salvaguardar la integridad física de aquélla), y su carácter continuo está asegurado por la presencia de un cuerpo victimal plural, en cuyo interior cada cuerpo individual no es más que un miembro fácilmente reemplazable. Presencia física, real, en la escena, presencia potencial en la reserva del serrallo. La potencialidad se extiende en última instancia a todo el orbe: el mundo entero es una gran reserva destinada al consumo energético del libertino.

El protagonismo victimal, que puede presentar un cáracter individual (el resto de las víctimas constituye entonces una serie de refuerzos especulares) puede ser, asimismo, compartido. En este caso, la formación de un cuerpo único entre las diferentes víctimas protagonistas puede preceder a la acción o bien sincronizarse con ella, en cuyo caso se va adicionando progresivamente cada nueva víctima y el cuerpo se va recomponiendo hasta llegar al resultado final.

La figura victimal central, simple o compuesta, es la que aparece de manera preferente en la formación del cuerpo libertino, pues permite la inserción de un tema, en la acepción ideológica del término, a partir del cual se construye la anecdótica del castigo (el cuerpo libertino no es tan solo una máquina, sino un complejo significante), centrándose éste sobre alguno de los puntales de la moral del statu quo. Ello no excluye, sin embargo, otro tipo de formación, carente de protagonismo, en el que todas las víctimas se sitúan al mismo nivel. El ataque se efectúa entonces en serie.

Del mismo modo, en la máquina erótica, macrocuerpo global, la presencia libertina tiene lugar, de manera preferente, a partir de una pluralidad de agentes.

10 «Nous ne sommes pas assez, dit Noirceuil, qui goùtait peu les plaisirs solitaires. Non, laissemoi; il t'en cuirait peutêtre, si tu prétendais à l'honneur de me faire décharger toute seule; mes passions concentrées sur un point unique ressemblent aux rayons de l'astre réunis par le verre ardent: elles brûlent aussitôt l'objet qui se trouve sous le foyer». Historie de Juliette ou les prospérités du vice, Paris U.G.E., col. 10/18, 1979, vol. I, p. 233. 
Dos modos de conexión interna se establecen entonces principalmente, siendo ésta física, generando una compleja red de relaciones en la conformación de la figura erótica, o visual.

Conviene señalar que este último tipo de conexión no está ausente, en ningún caso, en la formación del cuerpo libertino (la vista es un órgano que incide directamente en la actividad erótica humana), pero es aquí el modo dominante, en función de un espectáculo central. La conexión visual puede producir un efecto de desdoblamiento especular, según el cual se representa exactamente lo mismo que se contempla. Cuando ni el espectáculo ni el protagonismo de un actor libertino principal existen, cada libertino construye su espectáculo propio, siendo cada uno un pequeño núcleo, conectándose entre sí mediante la red visual generada por la trayectoria múltiple de la mirada. La conexión más perfecta, sin embargo, se realiza a partir de una figura libertina central, sobre la cual se construye el grupo y se cierra, concentrando y multiplicando de este modo la energía.

A partir de los distintos modos de conexión contemplados se elabora, pues, el cuerpo libertino, como un cuerpo múltiple y a la vez uno («Il y avait des instants où tous ces corps semblaient n'en faire qu'un», observa Justine en el transcurso de una orgía ${ }^{11}$ ), donde los distintos miembros se integran en una máquina de energía.

La máquina, como señalábamos más arriba, constituye un sistema, una estructura donde cada uno de los diversos elementos que la componen desempeña una función. Las funciones se incriben en dos categorías, activa y pasiva. La primera está desempeñada por los «agents», que ocupan el lugar preferente (libertinos), así como los «fouteurs», máquinas eróticas que, dentro de la categoría del personal de servicio, no desempeñan normalmente una función victimal ${ }^{12}$. La segunda clase, «patients», está constituida por las víctimas y el resto del personal. Los agentes son los impulsores energéticos de la máquina; los pacientes se encargan del sostenimiento, como objetos de consumo, y del mantenimiento, como personal de servicio. La máquina, por su carácter funcional, permite un acceso rápido y cómodo a los cuerpos, y, lo que es más importante, eliminar cualquier tiempo perdido, vacío, de la actividad erótico-cruel. En función de ambos aspectos, los operarios del taller de erotismo se identifican por la fijación de su temporalidad - la edad - en el número. Ello, por una parte, procura una clasificación precisa, una rápida identificación; por otra, la absorción de una determinada parcela del tiempo del otro. Al final de la sesión, las distintas edades habrán desfilado por la máquina libertina, creándose de este modo un espacio de pancronía. Por otra parte, si bien la estructura fundamental de la máquina no varía en el transcurso de una misma escena, los elementos que la componen son sustituibles, y cada libertino introduce variaciones en el modelo, adaptándolo a sus necesidades específicas. Las víctimas varían constantemente, lo que procura al libertino un cuerpo siempre fresco, siempre dispuesto, pero, principalmente, permite elegir: es la facultad misma de la elección lo que la maquina ofrece.

11 Justine ou les malheurs de la vertu, O.C., vol. III, p. 305.

12 Véase el trabajo de R. Barthes, Sade, Fourier, Loyola, Paris, Le Seuil, «Tel Quel», 1971. 
Su perfecto funcionamiento esta asegurado por el personal encargado de la vigilancia y el cuidado de los distintos mecanismos, sometiéndose a una energetización progresiva, en función del principio de aceleración ${ }^{13}$, hasta que la saturación revienta la capacidad de resistencia, produciendo la «descarga» orgásmi$\mathrm{ca}$, tras la cual se abre de manera inmediata un nuevo ciclo: al tiempo que consumación, el estallido abre paso a una nueva creación, del mismo modo que el universo, animado por el principio del movimiento (noción clave en la física de la época), está sometido a una mutación incesante.

La máquina erótica genera su propio tiempo, como genera su propio ritmo. El movimiento vibratorio interno y polifónico desarrola una evolución in crescendo hasta llegar al acorde (marcado por la tensión constante hacia un éxtasis sincrónico) que finaliza la secuencia y determina el principio de la siguiente.

A lo largo del proceso se produce una dialéctica entre movimiento y fijación. «Fixer l'attitude» es una de las tareas del trabajo erótico, y constituye una necesidad básica, pues de este modo la acción puede realizarse de manera perfecta, al tiempo que se evita cualquier pérdida de energía: ésta se aprovecha al máximo, en una subversión paradójica del concepto de utilidad.

La fijación, contra lo que pudiera parecer, no excluye el movimiento, sino todo lo contrario: es el movimiento en su propio devenir lo que se fija, en un intento de aprehender el tiempo desde su propia esencia; la composición global se mantiene, pero está animada por un prodigioso movimiento interno.

El principio de sincronía no sólo se aplica al final de la secuencia, sino en su funcionamiento interno sobre el cuerpo victimal (es, por otra parte, uno de los elementos donde radica el encanto visual del cuadro contemplado). Distintos agentes realizan la misma operación sobre varias víctimas, o bien un único agente es capaz de multiplicar su acción sobre varios cuerpos a la vez: la sincronía no sólo produce un efecto de condensación, sino, al mismo tiempo, de multiplicación. La precisión de la máquina erótica construida en el macrocuerpo libertino es tal que incluso las necesidades físicas exigidas de los sujetos hacen aparición al mismo tiempo ${ }^{14}$. De este modo, el control del cuerpo del otro por el libertino es absoluto, ejerciéndolo, asimismo, sobre el propio cuerpo, que se automatiza: tanto la víctima como el libertino son dos autómatas ${ }^{15}$.

En el interior de la máquina erótica, el propio desgaste genera energía, en un sistema centrífuga de autoalimentación, de tal manera que la producción del fluido espermático, «fluide électrique», se inserta en un proceso indetenible de amplificación energética. La máquina de la enería se construye, pues, como es-

13 Mediante la aceleración se satura por completo el tiempo de la acción erótica: «L’accélération est, en somme, au temps ce que la saturation est à l'espace», M. Hénaff, "Le principe d'accélération», in Sade, l'invention du corps libertin, Paris, P.U.F., 1978, p. 150.

14 «A peine nos six paillards furent-ils rassemblés au retour de cette infernale expédition, que les duègnes annoncèrent qu'elles avaient envie de chier». La Nouvelle Justine, O.C., vol. VII, p. 82.

15 La mejor ensoñación al respecto la encontramos en la máquina (mecánica) de Minski, en la historia de Juliette, que permite, de un sólo golpe, ejecutar dieciséis muertes diferentes (máquina perfecta, que no sólo permite la operación de condensación y multiplicación, sino, al mismo tiempo, la refracción). 
tructura de la paradoja. La actividad erótico-cruel se sitúa en una dinámica no tan sólo sin detención ni finitud, sino, además, de carácter expansivo: a mayor desgaste, mayor adquisición de potencia energética para abrir un nuevo ciclo. A partir de la acción de la energía, en la ensoñación del Yo en la Historia que podemos extraer del metadiscurso filosófico sadiano, se valoran las nociones de utilidad y rentabilidad, lo cual lleva a una ensoñación positiva del trabajo, que se inscribe en la constelación semántica de la felicidad. La acción de la energía, en la ensoñación del Yo en el Cosmos, genera curiosamente el proceso contrario: se rechaza todo aquello que signifique trabajo y se subvierte el concepto a partir de la práctica erótico-criminal. Ningún libertino, por definición, trabaja; su status socioeconómico le exime de dicha práctica, o bien la pervierte a partir del robo y el fraude, o la subvierte enteramente aplicando los mecanismos mercantilistas del sistema (así, por ejemplo, el negocio libidinal de Saint-Florent en La Nouvelle Justine). El libertino es el gran parásito del corpus social.

De este modo, asistimos a una valoración del elemento gratuito frente a todo aquello que signifique rentabilidad para el statu quo. En función de ello, se reivindica, hasta el paroxismo, la gratuidad del sexo, no sólo desde el punto de vista del resultado generador de la acción inserta en la dinámica de la propagación (entre otras razones, es lo que justifica la presencia obsesiva de la sodomía), sino en función del otro, como dialéctica negada, com acción intransitiva (la transitividad va a consistir, precisamente, en la destrucción). En el sistema de valores libertino el crimen más preciado será aquél donde la gratuidad sea mayor, y a ser posible absoluta, crimen auto-referencial, puro, generador de rentabilidad puramente erótica. Al erotismo transgresor el libertino consagra, pues realmente de consagración cabe calificarla, toda su existencia y sus capacidades activas y laboralmente explotables. Todo se dispone en torno al sexo, todo se monta y se estructura en torno a él y en función de él, siempre presente, siempre vivo, ya sea en la acción o en el pensamiento que la prepara y organiza. No existen tiempos perdidos para el libertino, quien, sin embargo, tiene todo el tiempo en sus manos ${ }^{16}$.

La máquina erótica, máquina de energía, diseñada para obtener una explotación y un rendimiento máximos, donde se evita cuidadosamente cualquier posible pérdida, tiene, paradójicamente, como única finalidad, el puro derroche (aquí radicaría para $\mathrm{M}$. Hénaff el humor absurdo de la paradoja de una máquina construida como autentico taller de producción). La paradoja se completa con la finalidad última del trabajo: la eyaculación es la gran «perte», resultante, sin embargo, de un proceso cuyo coste es elevado (como observa Hénaff, «coûter» es

16 La mayor falta que Bressac pueda reprocharle a su madre (culpable de pecado original ya por el solo hecho de serlo) es el apartarle de su espacio erótico vital:

«Rien n'avait pu determiner le jeune Bressac au service; tout ce qui l'écartait de son libertinage etait si insupportable a ses yeux, qu'il ne pouvait en adopter la chaîne.

Mme. de Bressac habitait, trois mois de l'année, cette terre ou Justine la trouva [...]. Quel supplice pour un homme abhorrant sa mère, et regardant comme perdus tous les moments qu'il passait éloignè d'une ville ou se trouvait pour lui le centre des plaisirs».

(La Nouvelle Justine, O.C., vol. VI, p. 172). 
un verbo corrientemente asociado), en un sistema donde no existe el paro ${ }^{17}$. La resultante es la subversión semántica construida sobre el concepto de utilidad.

El macrocuerpo libertino, máquina de energía, se construye como microestructura que, en función de una dinámica cósmica, reproduce la gran macroestructura de la Naturaleza. La dialéctica depredatoria que se instaura entre libertino y víctima — carne de consumo que alimenta la máquina erótica- reproduce la ley natural de destrucción-asimilación. El cuerpo libertino es entonces organismo vivo que se nutre de la carne de la víctima (la mujer es, además, «viande creuse», carne oximorónica de vacío que ha de ser absorbido por el libertino), como el tigre despedaza y devora a su presa ${ }^{18}$.

El cuerpo libertino se revela como organismo de la asimilación perfecta, integrando incluso los elementos de desecho en el proceso metabólico ${ }^{19}$ (lo cual, por otra parte, sería una manifestación más de la subversión del concepto de utilidad). La víctima es entonces, y de manera preferente, cuerpo enteramente explotable. Toda secreción, y hasta el aire de la víctima, se devora en la mesa de la orgía libertina, «repas du sang des hommes». El dolor se absorbe y reabsorbe en placer, y la crueldad se asimila a «délicatese» en un proceso de subversión semántica ${ }^{20}$. La absorción se extiende al tiempo del otro, siendo la muerte reasimilada en vida en el organismo libertino ${ }^{21}$.

El otro, la víctima, no es tan sólo el objeto que se somete a la depredación el libertino, sino que es ensoñado, además, como enemigo, desde el momento en que la mujer, víctima preferente, no es el otro yo semejante a mi mismo, sino un peligroso extranjero «toujours méchant, toujours dangereux; [...] individu bizarre, aussi distinct de l'homme que l'est le singe des bois» ${ }^{22}$ el otro inaprehensible que ha de ser destruido y cuya esencia ontológica ha de ser abolida, siendo reducida a una simple función en el interior de la máquina erótica, máquina de la contra-utilidad.

La resultante del proceso de subversión que en ella se construye lleva a la integración en la dinámica cósmica de la Naturaleza, tanto en función de la depredación como de la energía, cuyo derroche carece de finalidad práctica (la in-

17 «Nous ne chômons pas ici», dirá uno de los personajes de la historia de Juliette, Histoire de Juliette, Histoire de Juliette, vol. III, p. 19.

18 «Saint-Fond, très echauffé de vin et de férocité, s'y opposa en disant qu'il ne se sentait plus d'autre besoin que celui des tigres, et que, puisqu'il avait là de la chair fraîche, il fallait se hâter de la dévorer». Histoire de Juliette, vol. I, p. 335. El sátiro libertino posee, además, auténticas garras, armadas de «ongles crochus» con que despedazar a su presa.

19 Cf. M. Hénaff, «Les dépenses du corps: le 'foutre' et la 'merde', in op. cit., p. 209.

20 «[...] Sa bouche, imprimée sur celle de la patiente, semble respirer les douleurs qu’elle éprouve, pour en accroîte les plaisirs dont s'enivre sa délicatesse. «La Nouvelle Justine, O.C., vol. VII, p. 397.

21 «i...] Nous sommes maîtres de notre temps, rien ne nous presse, et les heures les mieux employées de la vie sont toujours celles où l'on l'arrache aux autres». Histoire de Juliette, vol. III, p. 275.

«O comble de l'horreur et de la cruauté! Il ne reste pus que le tronc: le féroce évêque s'y excite encore, il ne cesse de sodomiser ce cadavre sanglant. Il avait pourtant perdu son foutre... L'éxecrable mortel: il poursuivait, afin de retrouver la vie dans un corps auquel il vient de l'arracher. «La Nouvelle Justine, O.C., vol. VI, p. 360.

22 Ibíd., p. 157. 
fraestructura psicosensorial del aristócrata del lujo rechaza el concepto de utilidad forjado por la moral burguesa que, sin embargo, admite en el nivel de la superestructura ideológica): la única finalidad hacia la que se encamina toda la actividad de la Naturaleza es la creación. En este punto, la ensoñación en función de la Historia y la que se integra en el Cosmos entran en confrontación, pues el Yo sólo puede realizarse enteramente liberado del peso de la máquina social de producción (la Historia es eje abolido en La Nouvelle Justine, y enteramente distorsionado en la Histoire de Juliette, en función, precisamente, del libertinaje), negándose a una integración en el sistema como engranaje activo. El libertino subvierte el sistema, siendo él quien dispone el mecanismo de engranajes, convirtiéndose él mismo en engranaje vivo de la maquinaria cósmica. El espacio, entonces, se hace lujo, y la Orgía una obra de arte, una metáfora de la creación, al tiempo que una práctica de exorcismo, en la que, a partir de la subversión del código erótico occidental, la ensoñación de poder del Yo, en la liberación pulsional, es llevada hasta el límite. 